\title{
An Experimental Investigation of Mass Noun Types and Article Usage
}

\author{
Abdulrahman Alzamil ${ }^{1}$ \\ ${ }^{1}$ Department of Foreign Languages, Taif University, Taif, Kingdom of Saudi Arabia \\ Correspondence: Abdulrahman Alzamil, Department of Foreign Languages, Taif University, Taif, Saudi Arabia. \\ E-mail: dr.aa.alzamil@gmail.com
}

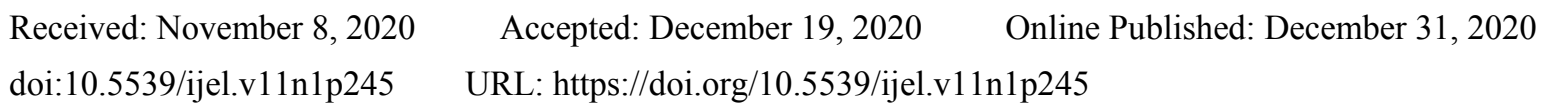

\begin{abstract}
Speakers of languages with article systems have to make different article choices in the case of mass versus countable nouns. This study addressed article use with different types of mass nouns (liquid, solid and abstract). It investigated: a) whether first language (L1) Arabic speakers used English articles accurately with mass nouns; and b) whether they were sensitive to different types of mass noun.

To address these issues, the study recruited twenty-seven English as a Foreign Language (EFL) Saudi-Arabic speaking participants and five native speakers of English, who formed a control group. Members of the experimental group were proficient to the elementary level, according to the Oxford Quick Placement Test. A written forced-choice elicitation task was administered to test their article use.

The findings showed that: a) the Arabic speakers performed similarly to the native speakers of English in liquid contexts, but differently in solid and abstract contexts; b) the Arabic speakers did not perform similarly across all types of mass nouns, as they were sensitive towards mass noun types; c) their article use was more accurate in liquid contexts than in solid and abstract contexts; and d) they faced difficulties using articles with mass nouns that can be pluralised in Arabic. These findings indicate that the use of articles with mass nouns should be examined in the light of their subtypes, as well as whether second language (L2) learners' L1 pluralise them or not.
\end{abstract}

Keywords: Arab EFL learners, mass nouns, articles, pluralisation, acquisition

\section{Introduction}

A plethora of studies has addressed the L2 acquisition of English articles (Hermas, 2019). Studies in the 1960s and 1970s focused on variations between L1 and L2 and how these were obstacles to successful L2 acquisition (Al-Qadi, 2017). Brown (2000) states that L1 transfer is a major culprit in the failure of L2 acquisition. Other researchers such as Kecskes and Papp (2000) believe that difficulties in L2 acquisition stem from the difficult nature of linguistic targets.

There are two types of noun in English: countable and uncountable. The former has both singular and plural forms, whereas the latter have only a mass form. The vast majority of studies that have addressed the use of English articles have focused on addressing singular and plural nouns and avoided mass nouns, probably due to the complexity of this issue (e.g., Feng, 2019; Ionin, Montrul, \& Santos, 2011; Pierce \& Ionin, 2011). The present study addresses the issue of complexity in the acquisition of English articles, and how this interacts with a speaker's L1 background (in this case Arabic), by examining the use of articles with different types of mass noun. Examining this issue may provide us with greater insight into the use of English articles with a noun type that has not received great deal of attention. The study asked the following questions:

1) Will L1 Arabic speakers use English articles accurately with mass nouns?

2) Will L1 Arabic speakers be sensitive to mass nouns types?

\section{Countability in Arabic and English}

This section sheds light on the distribution of countable and uncountable (mass) nouns in English. It goes on to discuss the way(s) articles are used with both countable and mass nouns in Arabic and English.

According to Yule (1998), countable nouns are those that can have individual units (e.g., door in English, and $b a b$ in Arabic) and plural units (e.g., doors in English, and abwab in Arabic). Conversely, uncountable nouns are 
those that cannot be pluralised (e.g., sugar in English and sukkar in Arabic). The distinction between uncountable and countable nouns is vague (Chierchia, 2010). This is because there is a difference between: a) how languages treat them; and b) the physical world. Regarding the former, language such as French and Italian have plural forms for the English word furniture, while it is treated as an uncountable noun in English and Arabic. Chierchia adds the basic distinction that countable nouns can occur with numeral expressions (e.g., two as in two doors). Countability is not dichotomous but rather a continuum (Allan, 1980). That is, there are nouns that can be regarded as uncountable in one context and countable in another. An example is the word tea.

Whether a noun is countable or not plays a role in using articles in English (Yule, 1998). Definite countable nouns (singular and plural) and uncountable nouns (mass) are preceded with the morphological marker the in English and $a l$ in Arabic. Conversely, singular indefinite countable nouns are marked with a/an in English and $\varnothing$ in Arabic, whereas plural and mass nouns are not morphologically marked in either language.

The next section discusses the definite and indefinite use of articles with mass nouns in English and Saudi Arabic. Since the majority of the participants in the current study speak Hijazi, the examples are written in Hijazi. It is worth mentioning that Saudi Arabic varieties (Hijazi and Najdi) are similar to each other syntactically but not so similar phonologically (Kramer \& Winchester, 2018).

\subsection{Countable Nouns}

The definite and indefinite use of articles for plural and singular nouns is illustrated below for English and Saudi Arabic:

English
a. The door is big. [definite singular]
b. The doors are big. [definite plural]
c. $A$ door is big. [indefinite singular]
d. $\varnothing$ Doors are big. [indefinite plural]

Saudi Arabic
a. al-bab kabir. [definite singular]
the-door big
'The doors are big.'
b. al-abwab kabirah. [definite plural]
the-doors big-FEM
'The doors are big.'
c. abwab kabirah. [indefinite singular]
door big
'A door is big.'
d. abwab kabirah. [indefinite plural]
doors big-FEM
'Doors are big.'

As can be noted from the above examples, article use in English and Arabic is similar except for the fact that indefinite singular nouns are not morphologically marked in Arabic.

\subsection{Uncountable Nouns}

This paper focuses on three major types of mass noun mentioned by a number of researchers (e.g., Ahmed, 2010; Chierchia, 2010). These are: a) liquid (e.g., water); b) solid (e.g., meat); and c) abstract (e.g., information). The definite and indefinite use of articles with uncountable (mass) nouns is illustrated below for English and Saudi Arabic.

English
a. The water is cold. [definite liquid mass]
b. I bought $\varnothing$ water. [indefinite liquid mass]
c. The meat is delicious. [definite solid mass] 
d. I bought $\varnothing$ meat. [indefinite solid mass]

e. The information is important. [definite abstract mass]

f. I need $ø$ information. [indefinite abstract mass]

Saudi Arabic

a. al-mujah bardah. [definite liquid mass]

the-water cold

'The water is cold.'

b. iftarit mujah. [indefinite liquid mass]

bought-I water

'I bought $\varnothing$ water.'

c. al-laham laðið. [definite solid mass]

the-meat delicious

'The meat is delicious.'

d. iftarit laham. [indefinite solid mass]

bought-I meat

'I bought meat.'

e. al-maSlumah muhimah. [definite abstract mass]

the-information important

'The information is important.'

f. Pahtad3 maSlumah. [indefinite abstract mass]

need-I information

'I need information.'

These examples show that English and Arabic use articles similarly with all types of mass noun.

\section{Literature}

L2 acquisition of English articles is deemed to be a difficult task. A number of studies in the literature have acknowledged L1 influence to be a key factor in the success or failure of the L2 acquisition of English articles (e.g., Al-Qadi, 2017; Avery \& Radisic, 2007; Hermas, 2019). Other studies have attributed the difficulty of English article acquisition to the complexity of articles' semantic properties (e.g., Abumlhah, 2016; Alzamil, 2016; Tania Ionin, Ko, \& Wexler, 2004; Sarko, 2009; Snape, 2006).

Studies that address the use of articles with mass nouns (in addition to singular and plural nouns) have found that these are problematic, as they look like singular nouns but should be treated like plural nouns (Abumlhah, 2016; Alzamil, 2016; Snape, 2006). However, these studies do not consider the consequences of the fact that mass nouns in English have subtypes. The mass items used in their studies were a mixture of types. By way of illustration, the next section reviews three studies that examined the L2 acquisition of mass nouns are reviewed.

Al-Mohanna (2014) conducted a study with 274 Saudi university-level students in Saudi Arabia (aged 18-23) to investigate their article uses. The data were gathered from written English compositions. One error that Al-Mohanna considered, which is relevant to the current study, was the use of indefinite articles with mass nouns. He found that the participants used the non-target article $a$ at a relatively high rate (25\%) with mass nouns. This is surprising, given that the Arabic language lacks an indefinite morphological marker. The study did not explicitly illustrate the frequency with which the definite article the was used with mass nouns; nor did it state what type of mass nouns the participants used, as it combined all the errors of use for all types of mass nouns.

Alzamil (2016) conducted a study with 56 Saudi Arabic ESL speakers and 66 Mandarin ESL speakers (Mandarin lacks articles). The participants had different levels of proficiency ranging from lower-intermediate to advanced. The instruments used were a mixture of written and oral tasks. He found that all the participants tended to use the non-target article $a$ with mass nouns, and attributed this to the similarity between mass and singular nouns, in that a marker of distinguish between different types of mass noun.

Al-Qadi (2017) examined the use of English articles by recruiting 50 Saudi-Arabic speaking participants at King 
Saud University. All participants were male first year students. The university conducted an English proficiency entrance test and the researcher gained access to their results. He focused on their misuse of English articles, finding that participants made more substitution errors than omission errors. He attributed this to the fact that Arabic has an article system and omission errors are expected from speakers whose languages are article-less.

It can be observed from the studies above that Arabic speakers face difficulties using English articles to the extent that they tend use the indefinite article $a$ with mass nouns. However, none of these studies considered whether distinguishing between the different types of mass noun can offer greater insight into the sorts of errors L2 learners make. This study looks at whether article use will differ according to the type of mass noun.

\section{Methodology}

A group of Saudi-Arabic speaking participants $(\mathrm{n}=27)$, who were EFL learners of English, was recruited in Saudi Arabia, in addition to a control group of native English speakers $(n=5)$, recruited in the UK. The Saudi-Arabic group were freshmen majoring in English at a Saudi university (aged 17-19) with an average age of 18.2 years. An Oxford Quick Placement Test was administered, which put them at the elementary proficiency level. A forced-choice elicitation task was administered. The task consisted of 40 English dialogues (24 target contexts and 16 distractors), with a blank in each. Participants had to select one of the three English articles (the, a/an, and $ø$ ). Half the 24 target mass nouns were definite and half indefinite. The same 12 items in the mass definite contexts were made indefinite to see if the participants would be sensitive to definiteness. The task also included 16 distractors with both singular and plural contexts but the study does not consider these. The dialogues were adapted from other studies (e.g., Alzamil, 2016; Snape, 2006). However, as those studies did not examine the subcategories of mass nouns, I had to make a considerable number of changes to their task items to make them fit this study's objective.

The distribution of contexts is summarised in the table below:

Table 1. Distribution of contexts in the forced-choice elicitation task

\begin{tabular}{llllll}
\hline \multirow{2}{*}{ Context } & Mass & & & $\begin{array}{l}\text { Singular } \\
\text { (distractors) }\end{array}$ & $\begin{array}{l}\text { Plural } \\
\text { (distractors) }\end{array}$ \\
\cline { 2 - 6 } & Liquid & Solid & Abstract & 4 & 4 \\
\hline Definite & 4 & 4 & 4 & 4 & 4 \\
\hline
\end{tabular}

An example of an indefinite solid mass noun is provided below:
A: John is in the Kitchen.
$\mathrm{B}$ : What is he doing?

A: He is making bread, and I cannot wait to taste it.

(Ø ( $\mathrm{a}$ the)

The participants gave their permission to participate in the study by signing consent forms. They then completed the Oxford Quick Placement Test and the forced-choice elicitation task. The placement test was timed (30 minutes) but the forced-choice elicitation task was not, so as to not pressure the participants into making random choices.

\section{Results and Findings}

This section consists of two subsections to address each research question. The first subsection compares the performance of Arabic speakers to that of native English speakers. The second is a comparison between mass contexts. The data were not normally distributed as shown by the kolmogorov-smirnov test $(p<0.05)$. Therefore, according to Field (2012), non-parametric tests should be run.

The native English speakers' mean score was $95.8 \%$. The mean percentage of the target articles in each of the six contexts is reported in the graph below for the Arabic-speaking participants. 


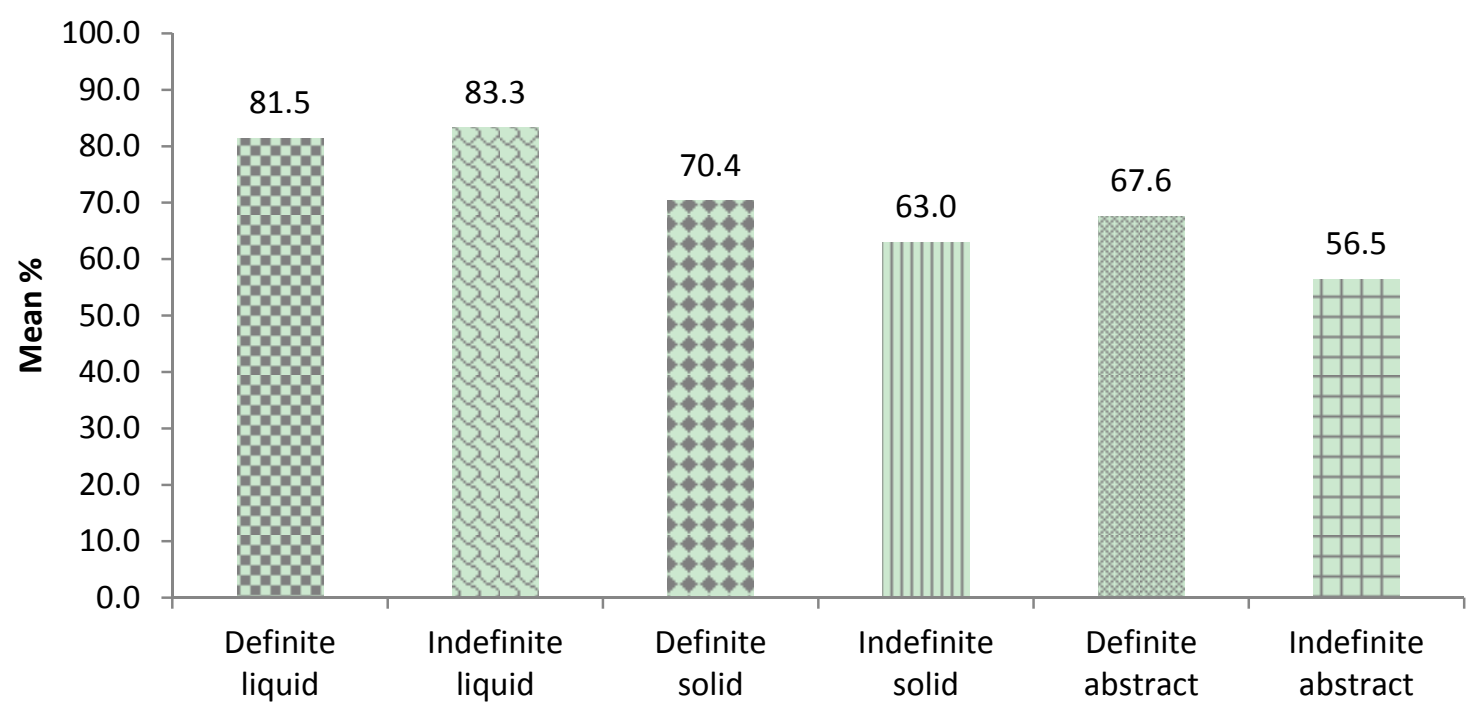

Figure 1. Mean percentages of target articles uses in all contexts

It can be noted from the graph that the Arabic speakers performed well in liquid definite and indefinite contexts and performed less accurately in the other contexts. To confirm this visual observation, the date were then analysed with SPSS (Version 25).

The target-like article choices of native speakers were compared to those of the Arabic-speaking participants in every context using Mann-Whitney tests and the results are reported below.

Table 2. Target-like use of articles: Arabic speakers vs. native speakers of English

\begin{tabular}{llll}
\cline { 2 - 4 } Definiteness & Liquid & Solid & Abstract \\
\hline Definite & $U=39.000$ & $U=15.000^{* *}$ & $U=22.500^{*}$ \\
(the) & $Z=-1.625$ & $Z=-3.096$ & $Z=-2.449$ \\
Indefinite & $U=44.000$ & $U=21.000^{*}$ & $U=.000^{* * *}$ \\
$(\varnothing)$ & $Z=-1.357$ & $Z=-2.520$ & $Z=-.3 .689$ \\
\hline
\end{tabular}

Note. ${ }^{*} \mathrm{p}<.05, * * \mathrm{p}<.01, * * * \mathrm{p}<.001$.

The experimental group is statistically significantly less accurate than the control group in definite and indefinite solid and abstract contexts. However, both groups performed similarly in liquid contexts.

Statistical comparisons using the Friedman test were conducted within the experimental group in the use of every article across the three contexts (liquid vs. solid vs. abstract). When a significant difference was found ( $\mathrm{p}$ $<.05)$, Multiple Wilcoxon Signed-Ranks tests were used after applying the Bonferroni correction $(\mathrm{p} \leqslant 0.017)$ to avoid making a Type 1 error, as recommended by Field (2012). The Friedman test results are reported below followed by the results for Wilcoxon Signed-Ranks tests.

Table 3. Friedman test results across the three contexts (liquid vs. solid vs. abstract)

\begin{tabular}{llll}
\hline Definiteness & the & $\mathrm{a}$ & $\varnothing$ \\
\hline Definite & $\chi^{2}(2)=5.927$ & $\chi 2(2)=6.099$ & $\chi 2(2)=2.935$ \\
& $p=0.052$ & $p=0.047$ & $p=0.230$ \\
Indefinite & $\chi 2(2)=0.933$ & $\chi 2(2)=20.458$ & $\chi 2(2)=18.659$ \\
& $p=0.627$ & $p<0.001$ & $p<0.001$ \\
\hline
\end{tabular}

The Friedman tests highlighted statistically significant differences in the use of $a$ in definite and indefinite contexts and in the use of $\varnothing$ in indefinite contexts. These results were further analysed to see between what pair of contexts the differences were. 
Table 4. Wilcoxon Signed-Ranks tests results for comparisons between contexts

\begin{tabular}{lllll}
\hline Definiteness & Article & Liquid vs. Solid & Liquid vs. Abstract & Solid vs. Abstract \\
\hline Definite & the & $Z=-2.556^{*}$ & $Z=-2.175$ & $Z=-.395$ \\
& a & $Z=-2.266$ & $Z=-1.144$ & $Z=-1.279$ \\
& $\varnothing$ & $Z=-.000$ & $Z=-1.755$ & $Z=-1.857$ \\
Indefinite & the & $Z=-.707$ & $Z=-.832$ & $Z=-.333$ \\
& a & $Z=-3.338^{*}$ & $Z=-3.834^{*}$ & $Z=-1.608^{*}$ \\
& $\varnothing$ & $Z=-3.251^{*}$ & $Z=-3.683^{*}$ & $Z=-1.028$ \\
\hline
\end{tabular}

Note. ${ }^{*} \mathrm{p} \leqslant 0 . \overline{017}$

Wilcoxon Signed-Ranks tests revealed a statistically significant difference in the target article the between definite liquid and solid contexts. Also, differences were found between indefinite liquid and both solid and abstract contexts in the use of $a$ and $ø$, and in the use of $a$ between indefinite solid and abstract contexts.

The test included four items of each type of mass noun. I visually observed that there was some overuse of the non-target article $a$ with some nouns in the solid and abstract contexts. It was found that some mass nouns in the task can be pluralised in Arabic, such as the word meat. Further analyses were therefore conducted by statistically comparing the nouns that can be pluralised in Arabic with those that cannot, in both solid and abstract contexts, to see if they were responsible for the low accuracy rates in these contexts. The items in the solid contexts that can pluralised in Arabic are cheese and meat, whereas rice and bread cannot. For abstract contexts, advice, evidence and information can be pluralised in Arabic, whereas confidence is not. None of the items in the liquid category can be pluralised. Wilcoxon Signed-Ranks tests were run by comparing article choice for the nouns that can be pluralised vs. the ones that cannot in solid and abstract contexts, and the results are reported below.

Table 5. Comparisons between nouns that can be pluralised in Arabic vs. the ones that cannot

\begin{tabular}{llll}
\hline Definiteness & Article & Solid & Abstract \\
\hline Definite & the & $Z=-2.355^{*}$ & $Z=-2.296^{*}$ \\
& a & $Z=-3.258^{* * *}$ & $Z=-2.828^{* *}$ \\
& $\varnothing$ & $Z=-1.633$ & $Z=-.333$ \\
Indefinite & the & $Z=-1.134$ & $Z=-2.449^{*}$ \\
& a & $Z=-2.392^{*}$ & $Z=-4.284^{* * *}$ \\
& $\varnothing$ & $Z=-1.642$ & $Z=-3.625^{* * *}$ \\
\hline
\end{tabular}

Note. ${ }^{*} \mathrm{p}<.05,{ }^{* *} \mathrm{p}<.01, * * * \mathrm{p}<.001$.

The results show that the participants were less accurate in the use of articles in contexts that can be pluralised in Arabic than those that cannot. This can be seen in all articles especially $a$.

\section{Discussion and Findings}

This section is divided into two parts to address each research question in turn:

1) Will L1 Arabic speakers use English articles accurately with mass nouns?

2) Will L1 Arabic speakers be sensitive to mass nouns types?

In respect of the first research question, the Arabic speakers performed similarly to the native English speakers in liquid contexts. Conversely, they were less accurate in solid and abstract contexts. These findings show that L2 English speakers do not perform similarly across all types of mass noun, and this leads to a discussion of the second research question, below.

Here, the Arabic-speaking participants showed sensitivity towards mass noun types. Intra-group comparisons showed that they more accurately used articles in liquid contexts than in solid and abstract contexts. This can be seen more in indefinite than in definite contexts. That is, they more accurately used the target the with definites than the target $\varnothing$ with indefinites, since they used the non-target article $a$ in indefinite solid and abstract contexts. This supports the assumption that they were not sensitive to definiteness, as they did not use the instead of the target $ø$. However, if they were not sensitive to definiteness, why were they more accurate in definite contexts than in indefinite contexts? This is because the in English is always used in definite contexts. Conversely, in indefinite contexts, there are two target articles $a$ and $\varnothing$, and choosing between them depends on the number feature (i.e., singular vs. plural and mass). Does this mean that the number feature is more difficult to acquire for 
L1 Arabic speakers? The L1 Arabic speakers in this study found it difficult to choose the target article with nouns that can be pluralised in Arabic. This supports the assumption that there is L1 transfer in the way that Arabic speaking English learners acquire nouns that can be pluralised in Arabic.

It is crucial to consider the fact that mass nouns have subcategories when attempting to explain and predict how L2 learners will use articles. This suggests that researchers should not treat mass nouns as a single type, and that mass nouns should be carefully considered before being included in written tasks. This illustrates why a number of researchers have had difficulty explaining article misuse with mass nouns (e.g., Al-Mohanna, 2014; Al-Qadi, 2017; Alzamil, 2016). This leads to a situation where mass nouns are not problematic for L2 learners because they look like singular nouns, as a number of researchers proposed (e.g., Alzamil, 2016; Snape, 2006), but because: a) they are not one type; and b) L2 learners' L1s affect how L2 learners' use articles with mass nouns.

\section{Conclusion}

This study has examined L1 Arabic speakers' English article use with different types of mass nouns to see whether they: a) use articles correctly; and b) are sensitive to mass noun types. Concerning syntactic properties, mass nouns are identical to singular nouns, but article-wise they are treated like plural nouns (Zamparelli, 2019).

Twenty-seven Saudi-Arabic speaking participants, along with a control group of five native English speakers, took part in the study. They all completed a written task to investigate their article use. It was found that: a) they performed similarly to the native speakers of English in liquid contexts, but not in other contexts; b) they were sensitive towards mass noun types and to whether they can be pluralised in Arabic. This shows the importance of considering mass noun subtypes before using them to examine article use.

The study suffers from shortcomings related to its small sample size and limited number of instruments. Future studies are recommended, using a larger sample size and more than one task to draw stronger conclusions regarding the use of articles with different types of mass nouns.

\section{References}

Abumlhah, M. A. (2016). The role of input in the acquisition of English articles by L1 Najdi Arabic speakers. Unpublished doctoral dissertation. University of Leeds, Leeds, UK.

Ahmed, A. H. (2010). Students' problems with cohesion and coherence in EFL essay writing in Egypt: Different perspectives. Literacy Information Computer Education Journal, 1(4), 211-221. https://doi.org/10.20533/licej.2040.2589.2010.0030

Al-Mohanna, A. D. M. (2014). Errors in the usage of the English definite/indefinite articles among Saudi university-level students. International Journal of Arts \& Sciences, 7(3), 79-95.

Al-Qadi, M. M. (2017). English article system errors among Saudi Arab EFL learners: A case of the preparatory year English program learners of King Saud University. Language \& Translation, 5(1), 69-77.

Allan, K. (1980). Nouns and countability. Language, 56(3), 541-567. https://doi.org/10.2307/414449

Alzamil, A. (2016). The second language acquisition of English indefiniteness and genericity by L1 Saudi Arabic and L1 Mandarin speakers. Unpublished doctoral dissertation. Newcastle University, Newcastle, UK.

Avery, P., \& Radisic, M. (2007). Accounting for variability in the acquisition of English articles. In A. Belikova, L. Meroni \& M. Umeda (Eds.), Proceedings of the 2nd Conference on Generative Approaches to Language Acquisition North America (GALANA) (pp. 1-11). Somerville, MA: Cascadilla Proceedings Project.

Brown, H. D. (2000). Principles of language learning and teaching. New Jersey: Prentice Hall Inc.

Chierchia, G. (2010). Mass nouns, vagueness and semantic variation. Synthese, 174(1), 99-149. https://doi.org/10.1007/s11229-009-9686-6

Feng, S. (2019). The acquisition of English definite noun phrases by Mandarin Chinese speakers. Studies in Second Language Acquisition, 41(4), 881-896. https://doi.org/10.1017/S0272263118000323

Field, A. (2012). Discovering statistics using IBM SPSS statistics. London: Sage publications.

Hermas, A. (2019). Mass generics in L3 English: Acquisition route and transfer recovery. International Journal of Language Studies, 13(2), 51-68.

Ionin, T., Ko, H., \& Wexler, K. (2004). Article Semantics in L2 Acquisition: The Role of Specificity. Language Acquisition, 12(1), 3-69. https://doi.org/10.1207/s15327817la1201_2

Ionin, T., Montrul, S., \& Santos, H. (2011). An experimental investigation of the expression of genericity in 
English, Spanish and Brazilian Portuguese. Lingua, 121, 963-985. https://doi.org/10.1016/j.lingua.2010.12.008

Kecskes, I., \& Papp, T. (2000). Foreign language and mother tongue. Mahwah, NJ: Erlbaum. https://doi.org/10.4324/9781410606464

Kramer, R., \& Winchester, L. (2018). Number and Gender Agreement in Saudi Arabic: Morphology vs. Syntax1. Paper presented at the Proceedings of the 17th Texas Linguistic Society, University of Texas.

Pierce, L., \& Ionin, T. (2011). Perception of Articles in L2 English. In L. Plonsky \& M. Schierloh (Eds.), Proceedings of the 2009 Second Language Research Forum (pp. 121-128). Somerville, MA: Cascadilla Proceedings Project.

Sarko, G. (2009). The Acquisition of the English Article System by L1 Syrian Arab and French Learners of English. Unpublished doctoral dissertation, University of Essex, Essex, UK.

Snape, N. (2006). The acquisition of the English determiner phrase by Japanese and Spanish learners of English. Unpublished doctoral dissertation, University of Essex, Essex, UK.

Yule, G. (1998). E0xplaining English Grammar: A Guide to Explaining Grammar for Teachers of English as a Second or Foreign Language. Oxford: Oxford University Press.

Zamparelli, R. (2019). Countability shifts and abstract nouns. In F. Moltmann \& L. Tovena (Eds.), Mass and Count in Linguistics, Philosophy, and Cognitive Science (pp. 1-27). Amsterdam, NL: Benjamins. https://doi.org/10.1075/lfab.16.09zam

\section{Copyrights}

Copyright for this article is retained by the author, with first publication rights granted to the journal.

This is an open-access article distributed under the terms and conditions of the Creative Commons Attribution license (http://creativecommons.org/licenses/by/4.0/). 